\title{
Identification of toxic metals in human embryonic tissues
}

Piotr Rzymski ${ }^{1}$, Przemysław Niedzielski², Barbara Poniedziałek ${ }^{1}$, Katarzyna Tomczyk ${ }^{3}$, Paweł Rzymski ${ }^{3}$

\begin{abstract}
${ }^{1}$ Faculty of Health Sciences, Poznan University of Medical Sciences, Poznan, Poland ${ }^{2}$ Department of Analytical Chemistry, Faculty of Chemistry, Adam Mickiewicz University, Poznan, Poland

${ }^{3}$ Department of Mother's and Child's Health, Gynecologic and Obstetrical University Hospital, Poznan University of Medical Sciences, Poznan, Poland
\end{abstract}

Submitted: 21 May 2015

Accepted: 24 July 2015

Arch Med Sci 2018; 14, 2: 415-421

DOI: 10.5114/aoms.2015.53915

Copyright $\odot 2016$ Termedia \& Banach

\section{Abstract}

Introduction: The cause of a significant number of miscarriages remains unexplained. There is a need to identify the potential role of environmental, dietary and lifestyle factors in the risk of pregnancy loss. The present study was the first to investigate the content of miscarried embryonic material with respect to eight metals (aluminium, cadmium, chromium, copper, manganese, nickel, lead and zinc).

Material and methods: Embryonic tissue samples $(n=20)$ were obtained from women undergoing misoprostol-induced removal of the embryo between the $6^{\text {th }}$ and $9^{\text {th }}$ week of gestation. The content of metals was analyzed using microwave-induced nitrogen plasma atomic emission spectrometry. Based on a short questionnaire, the smoking habits, dietary patterns and place of living of the investigated women were determined.

Results: The general mean content of metals $(\mu \mathrm{g} / \mathrm{g})$ decreased in the order copper (33.9) > manganese (24.7) > chromium (13.6) $>$ zinc (13.3) > aluminium (6.5) > nickel (3.0) > lead (2.9) > cadmium (2.5). Profoundly increased concentrations ( $p<0.05$ ) of the toxic elements aluminium (over 5 -fold), cadmium (over 2-fold) and lead (over 2-fold) were observed in samples obtained from former smoking women. The miscarried material in urban populations also revealed higher levels of cadmium (over 1.5 -fold) and lead (over 2-fold) compared to that obtained from women living in rural areas $(p<0.05)$. No associations with age or diet were found $(p>0.05)$.

Conclusions: This study identified increased levels of aluminum, cadmium and lead in miscarried embryonic material and suggests some causative factors.

Key words: human embryo, lead, cadmium, aluminium, miscarriage, cigarette smoking.

\section{Introduction}

Infertility and pregnancy loss affect a great number of women worldwide. Despite the fact that a variety of factors responsible for reproduction impairments have already been identified, the causes of a large number of these events remain unexplained [1, 2]. It is, however, known that quality of the environment may have a crucial effect on reproduction success [3], yet this effect is difficult to study.

The available data suggest that some widespread environmental pollutants such as toxic metals and some lifestyle-associated factors such

\author{
Corresponding author: \\ Piotr Rzymski PhD \\ Faculty of Health Sciences \\ Poznan University \\ of Medical Sciences \\ 8 Rokietnicka St \\ 60-806 Poznan, Poland \\ Phone: +48 618547651 \\ E-mail: rzymskipiotr@ump. \\ edu.pl
}


as tobacco smoking can have a highly adverse effect on pregnancy outcome [4]. As metals can be acquired orally or through inhalation, it seems reasonable to investigate the potential influence of inhabited environment, harmful habits (e.g. cigarette smoking) and diet on their concentrations in humans. A variety of studies have addressed this issue through investigation of urinary, blood, hair and semen samples [5-7] and, more recently, analyses of reproductive tissues [8]. Chemical analyses of embryonic material may be potentially useful in identifying factors leading to miscarriage or increasing its risk. Nevertheless, at present not very much is known about the presence of toxic metals in miscarried material or the variables that may influence it. So far, only one study has addressed this issue in relation to $\mathrm{Pb}$ content [9].

The aim of the present study was to identify eight metals - aluminium (Al), cadmium (Cd), chromium (Cr), copper $(\mathrm{Cu})$, manganese $(\mathrm{Mn})$, nickel $(\mathrm{Ni})$, lead $(\mathrm{Pb})$ and zinc $(\mathrm{Zn})$ - in human miscarried embryonic material. The hypotheses that age, type of inhabited area (urban or rural), smoking history

Table I. Characteristics of the studied group of women from whom the embryonic material was collected

\begin{tabular}{|c|c|}
\hline Parameter & Value \\
\hline Age, mean \pm SD [years]: & $31 \pm 5.0$ \\
\hline$>30$ years old, $n$ & 12 \\
\hline$<30$ years old, $n$ & 8 \\
\hline \multicolumn{2}{|l|}{ Place of living, $n$ : } \\
\hline Urban area & 14 \\
\hline Rural area & 6 \\
\hline \multicolumn{2}{|c|}{ Diet (frequency of product consumption): } \\
\hline \multicolumn{2}{|l|}{ Fish, $n$ : } \\
\hline Moderate & 3 \\
\hline Often & 8 \\
\hline Very often & 9 \\
\hline \multicolumn{2}{|l|}{ Meat, $n$ : } \\
\hline Moderate & 9 \\
\hline Often & 8 \\
\hline Very often & 3 \\
\hline \multicolumn{2}{|l|}{ Fruits, $n$ : } \\
\hline Moderate & 3 \\
\hline Often & 8 \\
\hline Very often & 9 \\
\hline \multicolumn{2}{|l|}{ Smoking history: } \\
\hline Non-smokers & 15 \\
\hline Former smokers: & 5 \\
\hline Years of smoking, mean \pm SD & $6.2 \pm 4.1$ \\
\hline $\begin{array}{l}\text { Smoking frequency range, } \\
\text { mean } \pm \text { SD [cigarettes per day] }\end{array}$ & $3.8 \pm 1.5$ \\
\hline
\end{tabular}

and dietary habits may influence observed concentrations were also tested. Importantly, the investigated elements included metabolically essential metals that are toxic at elevated levels or at certain valance states ( $\mathrm{Cr}, \mathrm{Cu}, \mathrm{Mn}$ and $\mathrm{Zn}$ ) as well as those that are non-essential and harmful ( $\mathrm{Al}, \mathrm{Cd}, \mathrm{Ni}$ and $\mathrm{Pb})$. Increased levels of all the studied metals have been shown to alter reproduction and fetal development $[10,11]$; therefore it is important to verify whether their concentration is in any way associated with miscarriage. Our preliminary study reports the presence of metals in embryonic material and suggests some of the factors that may be responsible for the increased levels of toxic elements that can lead to disruptive effects on the embryo or reproductive failure - a common ailment nowadays.

\section{Material and methods}

\section{Sample collection}

Samples $(n=20)$ were collected from women undergoing misoprostol-induced removal of the embryo between the $6^{\text {th }}$ and $9^{\text {th }}$ week of gestation in the Gynecologic and Obstetrical University Hospital in Poznan, Poland due to perinatal death. The exclusion criteria included occupational metal exposure, history of metal poisoning, anemia, alcoholism and drug addiction.

The material underwent routine pathologic examination in paraffin blocks with hematoxylin/ eosin staining. For the purpose of this study, only a small portion of this material (minimum $8 \mathrm{~mm}^{3}$ ) identified as chorionic tissue underwent analysis for metal concentrations. Thus, additional subsamples were collected using plastic devices and placed in plastic tubes filled with deionized water (Polpharma, Poland). After all the samples had been collected, the patients underwent routine uterine curettage and were allowed to return home $5 \mathrm{~h}$ later.

Based on a short questionnaire, the smoking habits and dietary patterns of the investigated women were specified. The studied group was also divided into women living in urban (City of Poznan, Poland) and rural (population density below 150 inhabitants per $\mathrm{km}^{2}$ ) areas. The study was approved by the local bioethical committee of the Poznan University of Medical Sciences, Poznan, Poland and every recruited woman signed a written consent form. The characteristics of the studied group are presented in Table I.

\section{Metal analyses}

To avoid metal contamination, all samples were handled using plastic instruments. Thawed tissues were dried in an oven at $40^{\circ} \mathrm{C}$ after being flushed twice with Milli-Q water (Millipore, USA), dried to a constant weight, weighed and digested with Su- 
prapur $14 \mathrm{~mol} / / \mathrm{HNO}_{3}$ (Sigma-Aldrich, Germany) in sealed plastic tubes using an oven $\left(80^{\circ} \mathrm{C}\right)$. The concentration of metals ( $\mathrm{Al}, \mathrm{Cd}, \mathrm{Cr}, \mathrm{Cu}, \mathrm{Mn}, \mathrm{Ni}, \mathrm{Pb}$ and $\mathrm{Zn}$ ) in the investigated samples was determined by a microwave-induced nitrogen plasma atomic emission spectrometer (MP-AES by Varian, Australia) equipped with a nitrogen generator as previously described [6]. Each determination was performed in triplicate; values were averaged. The calibration was performed using multi-element standard analytical solutions (Merck, Germany). Prior to the analysis, the detection method was validated with reference material BCR185R. The recovery rate exceeded $90 \%$ for all determined elements, at low relative standard deviation values (below 10\%).

\section{Statistical analyses}

The results were analyzed using STATISTICA 10.0 software (StatSoft, U.S.A.). Gaussian distribution was tested with the Shapiro-Wilk test, and because most of the data did not meet this assumption, non-parametric methods were employed. To evaluate differences between two independent groups the Mann-Whitney $U$ test was used. Relations between two datasets were determined with Spearman's rank correlation coefficient ( $r s) . P<0.05$ was considered as statistically significant.

\section{Results}

The main characteristics of the studied female group from which the samples were obtained are presented in Table I. All the studied metals were found in the miscarried material with their general mean content decreasing in the order $\mathrm{Cu}>\mathrm{Mn}>\mathrm{Cr}$ $>\mathrm{Zn}>\mathrm{Al}>\mathrm{Ni}>\mathrm{Pb}>\mathrm{Cd}$ (Table $\mathrm{II})$. Statistically significant positive associations were found between concentrations of $\mathrm{Pb}$ and $\mathrm{Cd}(p<0.05, r s=0.51)$, $\mathrm{Pb}$ and $\mathrm{Ni}(p<0.01, r s=0.61), \mathrm{Al}$ and $\mathrm{Cd}(p<0.05$, $r s=0.54)$, and $\mathrm{Ni}$ and $\mathrm{Cr}(p<0.05, r s=0.55)$.

Age was not related to the content of any of the studied elements in the embryonic material. Firstly, it was not significantly correlated with observed concentrations, and secondly, their levels did not differ between women aged < 30 and $>30$ years old. Moreover, none of the frequencies of fruit, fish or meat consumption were associated with the content of any studied element.

However, cigarette smoking was an important factor affecting the chemical composition of embryonic material. Former smokers revealed an over 5-fold higher Al content as well as 2-fold higher levels of $\mathrm{Pb}$ and $\mathrm{Cd}$. The concentrations of other metals did not differ between non-smoking and former smokers (Figure 1). Significant positive correlations were also found between years of cigarette smoking in the past and content of $\mathrm{Al}$ $(p<0.001, r s=0.73), C d(p<0.001, r s=0.68)$ and $\mathrm{Pb}(p<0.05, r s=0.51)$. Similarly, the number of cigarettes smoked per day in the past was also associated with concentration of $\mathrm{Al}(p<0.001, r s=0.69)$, $\mathrm{Cd}(p<0.01, r s=0.64)$ and $\mathrm{Pb}(p<0.05, r s=0.44)$.

The second factor identified as differentiating the chemical composition of collected material was the type of environment inhabited by the studied women. Compared to those living in rural areas, women inhabiting urban zones revealed a 1.5-fold and 2-fold greater content of $\mathrm{Cd}$ and $\mathrm{Pb}$ respectively compared to that obtained from those who resided in rural areas. The levels of the other studied metals did not differ between these two groups (Figure 2).

\section{Discussion}

Various factors have been implicated in the origin of pregnancy loss, among which are genetic, immunological, infectious and hormonal conditions. However, the role of the environment in this phenomenon is poorly understood. It is known that a wide range of environmental agents can affect physiological conditions and consequently increase the risk of miscarriage [12, 13]. It is also unclear whether toxic metals may accumulate in human embryos/fetuses in the early stage of pregnancy [9]. This is, however, plausible if one considers the early establishment of intervillous circulation in pregnant women and its gradual increase throughout the first trimester - a route through which oxygen and nutrients but also toxic agents (if present) may be supplied to the developing organism from the maternal blood [14]. Our study not only establishes the presence of one of the most widespread pollutants - toxic metals in the miscarried embryonic material but, more importantly, preliminarily suggests that certain environments or harmful lifestyle factors may potentially affect their concentrations in the embryo.

It should be noted that the present study, conducted on a relatively small sample size, contains

Table II. Level of metals ( $\mu \mathrm{g} / \mathrm{g}$ ) in human embryonic tissue collected from miscarried material between $6^{\text {th }}$ and $9^{\text {th }}$ week of gestation

\begin{tabular}{|lc|}
\hline Metal & Mean (range) \\
\hline $\mathrm{Al}$ & $6.5(1.2-37.1)$ \\
\hline $\mathrm{Cr}$ & $13.6(1.0-53.1)$ \\
\hline $\mathrm{Cd}$ & $2.5(1.2-5.3)$ \\
\hline $\mathrm{Cu}$ & $33.9(11.2-68.0)$ \\
\hline $\mathrm{Mn}$ & $24.7(10.2-47.8)$ \\
\hline $\mathrm{Ni}$ & $3.0(1.3-6.0)$ \\
\hline $\mathrm{Pb}$ & $2.9(1.1-7.2)$ \\
\hline $\mathrm{Zn}$ & $13.3(1.1-32.6)$ \\
\hline
\end{tabular}



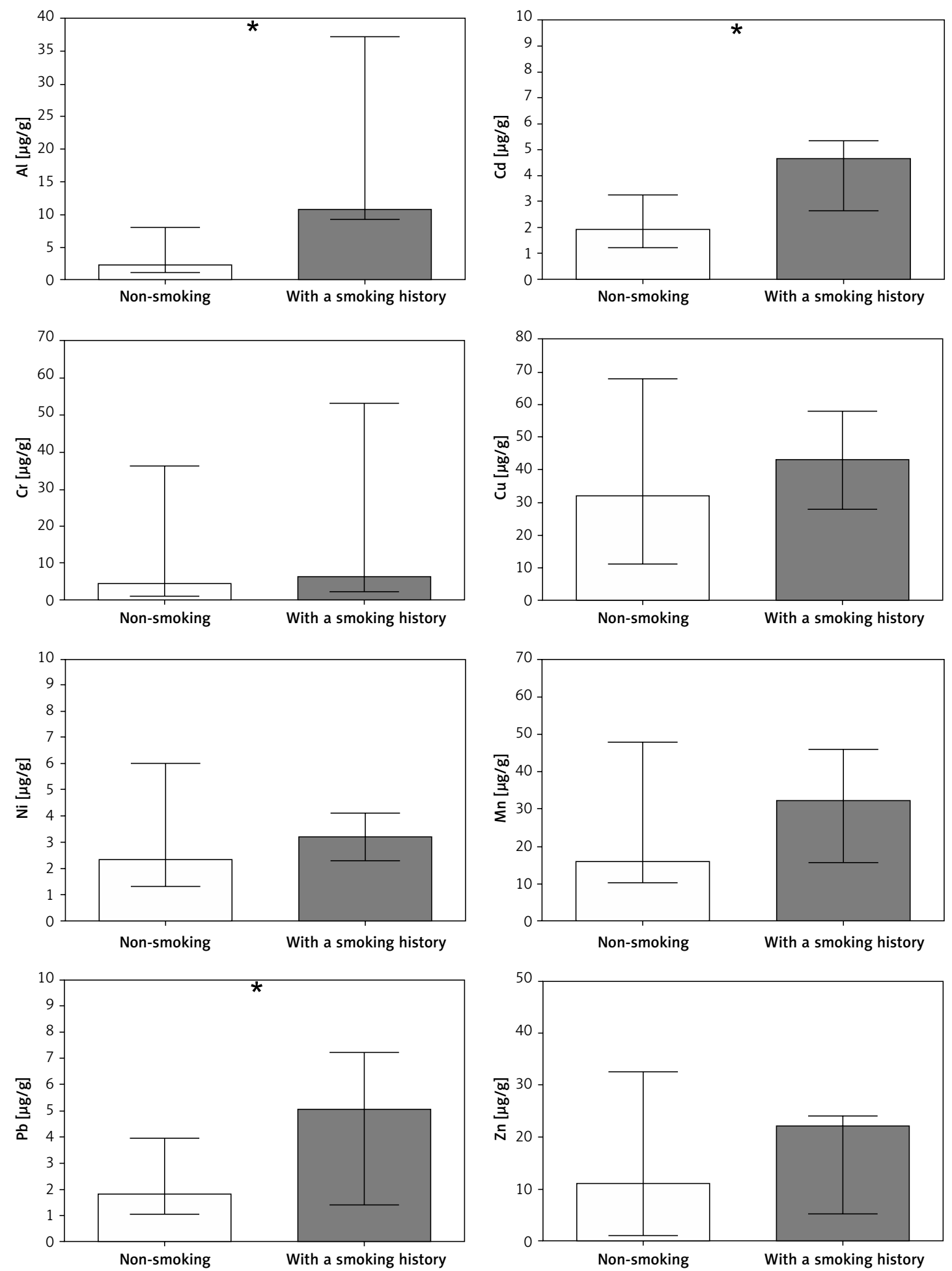

Figure 1. Content of metals in miscarried embryonic material collected from non-smoking women (white bars) and women with a smoking history (grey bars). Bars represent median, whiskers represent range, asterisks indicate statistically significant differences in metal content between groups

several limitations and in spite of statistically significant differences revealed between compared groups, its results should be treated cautiously. Although potential associations between exposures to $\mathrm{Al}, \mathrm{Pb}$ or $\mathrm{Cd}$ and miscarriage have been established $[15,16]$, it is not possible to directly assess the causality between the levels of ana- lyzed metals and pregnancy loss in the studied group of women. Moreover, despite the special care taken to separate the placenta from the embryo, there is still a possibility that certain parts of maternal tissues were not dissected and could have contributed to an overestimation of the observed concentrations. Nevertheless, the pres- 

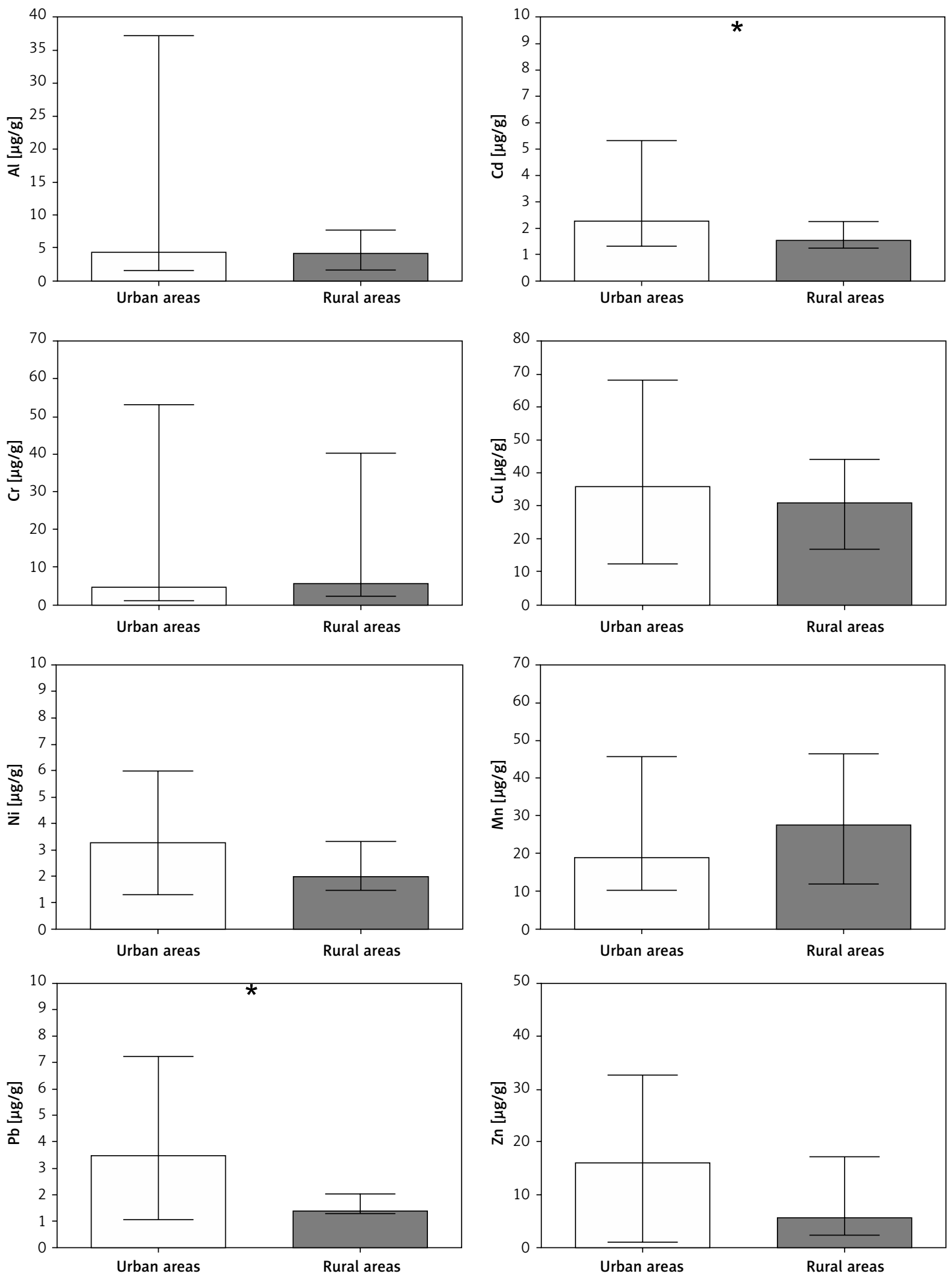

Figure 2. Content of metals in miscarried embryonic material collected from women living in urban (white bars) and rural (grey bars) areas. Bars represent median, whiskers represent range, asterisks indicate statistically significant differences in metal content between groups

ent study, at least partially, extends the existing knowledge on the relationship between lifestyle and environmental variables and the status of elements exhibiting certain reproductive toxicities. It should be stressed that there are no normative values for metal content in the human embryo. Therefore, the concentrations observed in the

present study may serve as a reference point in future investigations.

One of the most important findings of the present study is the increased level of $\mathrm{Al}, \mathrm{Cd}$ and $\mathrm{Pb}$ in embryonic samples miscarried by women with a smoking history compared to never smoking ones. Commercially available tobacco and 
cigarette smoke were previously found to represent an important single source of various toxic elements including $\mathrm{Cd}$ and $\mathrm{Pb}[17,18]$, and the link between blood or urinary metal levels and smoking frequency is well established [19, 20]. Although these elements are known to predominantly accumulate in kidneys, liver and bones, and possess long half lives [21, 22], it was recently found that their levels are increased in the reproductive tissues of women who had formerly smoked [8]. This, in turn, indicates that following their accumulation, partial re-release to the general circulation can occur over time - a phenomenon which, so far, has been associated with increasing age and hormone production, particularly during pregnancy [23]. Even though our study did not discover any relationship between female age and determined metal concentrations in miscarried material, the occurrence of increased levels of $\mathrm{Al}, \mathrm{Cd}$ and $\mathrm{Pb}$ in samples collected from formerly smoking women highlights that cigarette smoking, even in the past, may increase embryonic exposure to toxic metals. This finding is particularly relevant for health promotion and safe pregnancy programs.

Interestingly, Al ingested orally is poorly absorbed in the gastrointestinal tract (in the range of $0.1-1.0 \%$ of an oral dose) and usually undergoes rapid excretion. While the levels of Al contamination in tobacco products were not comprehensively studied, the inhalation route appears to play an important role in total Al absorption and balance [24]. Smokers and occupationally exposed individuals reveal increased levels of this element in blood, urine and hair [25]. Therefore, from the results of our study we conclude that former smokers could potentially represent a group at increased risk of embryonic exposure to Al.

The other important observation of the present study concerns the increased levels of $\mathrm{Al}, \mathrm{Cd}$ and $\mathrm{Pb}$ present in embryonic tissues collected from women inhabiting urban areas compared to those from rural areas. It has already been shown that human exposure to toxic agents, including metals, is elevated in urban environments [26]. Moreover, it was recently demonstrated that levels of $\mathrm{Cd}$ and $\mathrm{Pb}$ in maternal and umbilical cord blood are greater in populations living at urban sites [27]. The main route of potential exposure to toxic metals in urban environments includes inhalation of polluted air due to absorption of these elements on the surface of particulate matter (PM). As demonstrated, the concentrations of PM of micrometric diameters are often greater in urban areas compared to rural ones $[28,29]$. It was also shown that exposure to PM can increase the frequency of spontaneous abortions [30]. It should, however, be highlighted that metals are only one group of toxic pollutants associated with industrial and urban areas and that environmentally induced pregnancy loss can be a result of the synergistic effect of various chemical agents, including ozone, polycyclic aromatic hydrocarbon or nitrogen oxides [30].

Increased maternal and embryo exposures to $\mathrm{Al}, \mathrm{Cd}$ and $\mathrm{Pb}$, elements not known to play any biological role in living organisms, can increase the risk of pregnancy loss. As shown in a rodent experiment model, an excess of Al can lead to decreased serum content of estrogen, progestogen, testosterone, follicle-stimulating hormone, and luteinizing hormone [31]. Cd and $\mathrm{Pb}$ are also known to increase the generation of reactive oxygen species and reactive nitrogen species and lead to oxidative stress and associated damage to DNA, proteins, and lipids [21]. Some studies clearly indicate that the frequency of spontaneous abortion is higher in women with greater serum levels of $\mathrm{Cd}$ and $\mathrm{Pb}$ [16]. Although it is not possible to decide whether the increased metal levels found in former smokers and women living at urban sites actually contributed to pregnancy loss, it is beyond any doubt that an elevated embryo content of toxic elements may induce molecular damage and have an adverse effect on final pregnancy outcome [32].

In conclusion, the present study is the first to investigate the content of eight metals, important as regards human reproduction, in miscarried embryonic material. All the studied elements were detected, with $\mathrm{Cu}$ and $\mathrm{Cd}$ being decidedly the most and least abundant metal, respectively. Importantly, the materials collected from women with a smoking history were characterized by significantly increased levels of toxic metals (Al, $\mathrm{Cd}$ and $\mathrm{Pb}$ ) compared to never smoking woman. Similarly, the women inhabiting urban areas also revealed greater content of $\mathrm{Cd}$ and $\mathrm{Pb}$ in embryo than those from rural areas. These results suggest the potential associations between environmental quality as well as harmful habits, and the presence of toxic chemical agents that can induce reproductive toxicity.

\section{Conflict of interest}

The authors declare no conflict of interest.

\section{References}

1. Saravelos SH, Regan L. Unexplained recurrent pregnancy loss. Obstet Gynecol Clin North Am 2014; 41: 157-66.

2. Esmaeilzadeh S, Delavar MA, Basirat Z, Shafi H. Physical activity and body mass index among women who have experienced infertility. Arch Med Sci 2013; 9: 499-505.

3. Hutz RJ, Carvan MJ, Baldridge MG, Conley LK, Heiden TK. Environmental toxicants and effects on female reproductive function. Tren Reprod Bio 2006; 2: 1-11.

4. Zheng G, Zhong H, Guo Z, et al. Levels of heavy metals and trace elements in umbilical cord blood and the risk 
of adverse pregnancy outcomes: a population-based study. Biol Trace Elem Res 2014; 160: 437-44.

5. Callan AC, Hinwood AL, Ramalingam M, et al. Maternal exposure to metals - concentrations and predictors of exposure. Environ Res 2013; 126: 111-7.

6. Hinwood AL, Callan AC, Ramalingam M, et al. Cadmium, lead and mercury exposure in non smoking pregnant women. Environ Res 2013; 126: 118-24.

7. Guzikowski W, Szynkowska MI, Motak-Pochrzęst H, Pawlaczyk A, Sypniewski S. Trace elements in seminal plasma of men from infertile couples. Arch Med Sci 2015; 11: 591-8.

8. Rzymski P, Rzymski P, Tomczyk K, et al. Metal status in human endometrium: relation to cigarette smoking and histological lesions. Environ Res 2014; 132: 328-33.

9. Borella P, Picco P, Masellis G. Lead content in abortion material from urban women in early pregnancy. Int Arch Occup Environ Health 1986; 57: 93-9.

10. Rzymski P, Tomczyk K, Rzymski P, Poniedziałek B, Opala T, Wilczak M. Impact of heavy metals on the female reproductive system. Ann Agric Environ Med 2015; 22: 259-64.

11. Tsuchiya $H$, Shima S, Kurita $H$, et al. Effects of maternal exposure to six heavy metals on fetal development. Bull Environ Contam Toxicol 1987; 38: 580-7.

12. Hosseini SA, Farsi Zaban M. Risky behaviors and life status as risk factors for spontaneous abortion. Int J High Risk Behav Addict 2014; 3: e17635.

13. Mao GH, Feng Z, He Y, Huang YR. Comparisons of the effects of long-acting and short-acting GnRH agonists on embryo quality, endometrial thickness and pregnancy rate in human in vitro fertilization. Arch Med Sci 2014 10: 161-6.

14. Mercé LT, Barco MJ, Alcázar JL, Sabatel R, Troyano J. Intervillous and uteroplacental circulation in normal early pregnancy and early pregnancy loss assessed by 3-dimensional power Doppler angiography. Am J Obstet Gynecol 2009; 200: 315.e1-8.

15. Gomez M, Domingo JL, Llobet JM. Developmental toxicity evaluation of oral aluminum in rats: influence of citrate. Neurotoxicol Teratol 1991; 13: 323-8.

16. Ajayi OO, Charles-Davies MA, Arinola OG. Progesterone, selected heavy metals and micronutrients in pregnant Nigerian women with a history of recurrent spontaneous abortion. Afr Health Sci 2012; 12: 153-9.

17. Caruso RV, O'Connor RJ, Stephens WE, Cummings KM, Fong GT. Toxic metal concentrations in cigarettes obtained from U.S. smokers in 2009: results from the International Tobacco Control (ITC) United States survey cohort. Int J Environ Res Public Health 2013; 11: 202-17.

18. Pappas RS, Polzin GM, Watson CH, Ashley DL. Cadmium, lead, and thallium in smoke particulate from counterfeit cigarettes compared to authentic US brands. Food Chem Toxicol 2007; 45: 202-9.

19. Stojanović D, Nikić D, Lazarević K. The level of nickel in smoker's blood and urine. Cent Eur J Public Health 2004; 12: 187-9.

20. Richter PA, Bishop EE, Wang J, Swahn MH. Tobacco smoke exposure and levels of urinary metals in the U.S. youth and adult population: the National Health and Nutrition Examination Survey (NHANES) 1999-2004. Int J Environ Res Public Health 2013; 6: 1930-46.

21. Barregard L, Fabricius-Lagging E, Lundh T, et al. Cadmium, mercury, and lead in kidney cortex of living kidney donors: Impact of different exposure sources. Environ Res 2010; 110: 47-54.

22. Miculescu F, Miculescu M, Ciocan LT, et al. Comparative studies regarding heavy elements concentration in human cortical bone. Dig J Nanomater Bios 2011; 6: 1117-27.

23. Gulson BL, Mahaffey KR, Jameson CW, et al. Mobilization of lead from the skeleton during the postnatal period is larger than during pregnancy. J Lab Clin Med 1998; 131: 324-9.

24. Bertram J, Brand P, Hartmann L, et al. Human biomonitoring of aluminium after a single, controlled manual metal arc inert gas welding process of an aluminium-containing worksheet in nonwelders. Int Arch Occup Environ Health 2015; 88: 913-23.

25. Unkiewicz-Winiarczyk A, Gromysz-Kałkowska K, Szubartowska E. Aluminium, cadmium and lead concentration in the hair of tobacco smokers. Biol Trace Elem Res 2009; 132: 41-50.

26. Bolté S, Normandin L, Kennedy G, Zayed J. Human exposure to respirable manganese in outdoor and indoor air in urban and rural areas. J Toxicol Environ Health A 2004; 67: 459-67.

27. Röllin HB, Rudge CV, Thomassen $\mathrm{Y}$, Mathee A, Odland $J \emptyset$. Levels of toxic and essential metals in maternal and umbilical cord blood from selected areas of South Africa - results of a pilot study. J Environ Monit 2009; 11: 618-27.

28. Aldabe J, Elustondo D, Santamaria C, et al. Chemical characterisation and source apportionment of PM2.5 and PM10 at rural, urban and traffic sites in Navarra (North of Spain). Atmos Res 2011; 102: 191-205.

29. Rogula-Kozłowska W, Klejnowski K. Submicrometer aerosol in rural and urban backgrounds in southern Poland: primary and secondary components of PM1. Bull Environ Contam Toxicol 2013; 90: 103-9.

30. Enkhmaa D, Warburton N, Javzandulam B, et al. Seasonal ambient air pollution correlates strongly with spontaneous abortion in Mongolia. BMC Pregnancy Childbirth 2014; 14: 146.

31. Wang N, She Y, Zhu Y, et al. Effects of subchronic aluminum exposure on the reproductive function in female rats. Biol Trace Elem Res 2012; 14: 382-7.

32. del C Díaz M, González NV, Gómez S, Quiroga MA, Najle R, Barbeito CG. Effect of a single dose of cadmium on pregnant Wistar rats and their offspring. Reprod Domest Anim 2014; 49: 1049-56. 